\title{
La vie on azur: El spleen del albatros
}

\author{
La vie on azur: the spleen of the albatross
}

\section{Aldo Vivar-Mendoza ${ }^{1}$}

\section{Resumen}

El 2021 es el año del bicentenario del nacimiento de Charles Baudelaire, pretexto ideal para repasar la vida y obra de un poeta que describió con crudeza los abismos y recovecos de la sociedad parisina de mediados del siglo XIX y que, como una paleta de colores, mostró los matices de la condición humana. Baudelaire tuvo una vida corta e intensa, lo suficiente para dejarnos una obra deslumbrante y propicia para tiempos de crisis como los de ahora.

Palabras claves: Baudelaire, poesía, aniversario, nacimiento.

\section{Abstract}

The year 2021 celebrates 200 hundred years of the birth of Charles Baudelaire, ideal excuse to review the life and works of a poet who crudely described the abysses and labyrinths of the Parisian society in the mid of the XIX century, and, as a color palette, showed the nuances of the humankind. Baudelaire's life was short and intense but long enough to surrender a dazzling artwork, suitable for times of crisis like now.

Keywords: Baudelaire, poetry, anniversary, birth.

1 Médico internista. Hospital Nacional Arzobispo Loayza. Facultad de Medicina, Universidad Peruana Cayetano Heredia, Lima, Perú.

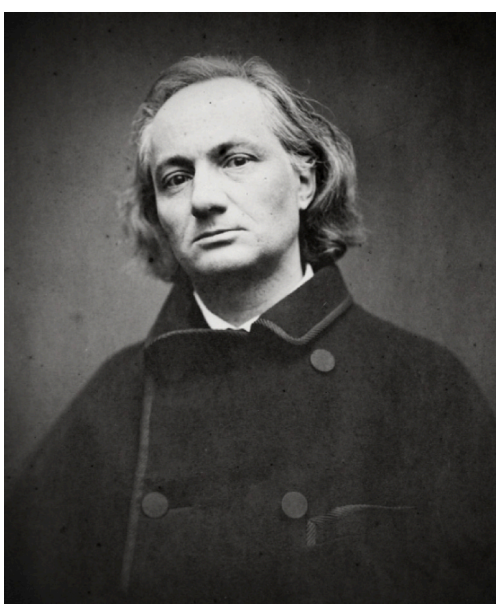

Charles Baudelaire (1821-1867)

Charles Baudelaire cumple 200 años este 2021, aquel poeta pluviôse, irritè, contre le ville entière, que llevaba como buen flaneur su melancolía a rastras. A decir de Charles Asselinau "el único escritor [...] de quien se puede pronunciar, sin que resulte ridícula, la palabra genio".

Baudelaire nació en 9 de abril en el 13 de la rue Hautefeuille en París, hijo de Joseph Francois Baudelaire, un sexagenario discípulo de filósofos y amante de la pintura, y su madre CarolineArchenbaut Delayis. El pequeño Charles quedó huérfano de padre en febrero de 1827; tiempo después la 
viuda Caroline se volvió a casar en noviembre de 1828 con el comandante de la Legión de Honor, Jacques Aupick, quien luego de sofocar revueltas en París sería futuro embajador plenipotenciario del II Imperio francés en Constantinopla, luego en Madrid, para en 1857 convertirse en senador y también en una figura paterna aplastante.

Las relaciones entre el pequeño Charles y su padrastro no eran buenas por lo que fue enviado a estudiar a un internado en Lyon, el Colegio Real, donde en 1837 quedó segundo en un concurso sobre versos latinos. En el colegio ya mostraba aquel rasgo singular, algo cínico, de extrema melancolía y con un destino solitario. En abril 1839 es expulsado del colegio por mala conducta; sin embargo, es readmitido en agosto para recibir el grado de bachiller.

En 1840, Baudelaire vuelve a París, el mismo año que las cenizas de Napoleón llegan al cementerio des Invalides. Charles se instala en la vida libre y bohemia de la ciudad, conociendo a Gerard de Nerval, Balzac y otros poetas. Por ese tiempo se involucra con una prostituta del Barrio Latino, llamada Sara. Debido a esa vida disipada, su padrastro al no poder corregir aquel comportamiento decide enviarlo en un viaje en barco a las Indias, con paradas en las islas Mauricio y Reunión.

Ya en la mayoría de edad, en1842, regresa a París a recibir la herencia paterna (100 000 francos). Esta afluencia de dinero le hace más sencillo regresar a la vida disipada, donde se reencuentra con Jeanne Duval, joven mulata de origen haitiano que, por ese tiempo, era amante de un escritor. Jeanne se convierte en compañía y musa de sus primeros poemas; sin embargo, ella no lo amaba. Por esos años comienza las tareas de escritor, crea un drama en verso, en colaboración con Prarond, publica en diversas revistas y se convierte en crítico de arte. También es la época en que comienza a adquirir deudas y futuros problemas financieros.
En 1844, debido a que ya gastó la mitad de la herencia, es demandado por un representante de la familia, el notario Narcisse Ancelle y por orden judicial se dispone que Baudelaire no puede hacer más gastos libremente y se le asigna una pensión de 200 francos mensuales. La relación con el notario es hostil y hasta insoportable, como la que tenía con su padrastro.

En 1845, con 24 años de edad, tiene su primer gesto suicida. Días antes, en una carta de despedida al notario Ancelle, revela sus intenciones, deja escrito que se mata "no por aquella perturbación que algunos llaman pena sino por la fatiga de tener que dormirse y despertarse", así como porque se cree inmortal. Esa noche, estando acompañado de Jeanne en un local de la rue Richelieu, intenta apuñalarse para luego desmayarse. Al despertar es llevado a la comisaría.

En 1847 descubre parte de la obra de Edgar Allan Poe, quedando embelesado por su concisión y por la capacidad de expresión que hay en ella, además de presentar la perversidad de la vida humana. El cuento que lo marcó a decir de su amigo y biógrafo Charles Asselinau, fue "El gato negro". Su primer artículo sobre Poe en La liberté de penser fue publicado el 15 de julio de 1848. Gracias a ese primer encuentro Baudelaire se dedicó en los siguientes años a tres cosas: perfeccionar su inglés, recopilar obras y apuntes biográficos de Poe -fallecido en circunstancias oscuras en 1849, y traducir sus obras que luego publicaría. El conocer sobre la vida azarosa de Poe -una tormenta permanente- lo convirtió en su alma gemela. Para Baudelaire, la marginalidad de Poe, denostado por el sistema burgués, era una imagen especular de lo que sucedía en la Francia de entonces, donde un golpe de estado había llevado a la burguesía conservadora al poder. Para un literato como él se le abrían las puertas de la marginalidad y la denuncia, con esa evidencia nacía la imagen del poeta maldito al otro lado del Atlántico. 
Así, en 1852, Baudelaire publica "Edgar Allan Poe, su vida, sus obras", en la Revue de París. En 1853 las traducciones de "El cuervo" y de "El gato negro”. En 1856 y 1857 publica en el periódico Les pays las traducciones con el título de "Histoires Extraordinaires”. Poe se convierte por analogía personal en el siniestro alter ego de Baudelaire, a quien denominó "el escritor de los nervios"

El 1 de junio de 1855 se publica en la Revue des Deux Mondes los primeros 18 versos de "Las flores del mal". Baudelaire luego logra un contrato para la publicación del poemario bajo la forma de libro. Finalmente, se publica el 25 de junio de 1857 como libro "Las flores del mal" -dos meses antes había muerto su padrastro Aupick- y Baudelaire titubeó muchísimo de enviar el manuscrito a su madre. El poemario es una mezcla de imágenes que conjugan la belleza y la melancolía y que dibujan los mas iluminados y oscuros recovecos de la condición humana, de poemas que fueron escritos en hoteles, en bares donde se consumía hachís y opio, en burdeles, y son el resultado de una vida a salto de mata sumada a una situación económica siempre precaria. A pesar de ello, Baudelaire siempre tenía las camisas limpias, aunque sus zapatos tuviesen agujeros rellenados con cartón o tela. Un dandy con los pies fríos.

La creación es un templo de pilares vivientes que a veces deja escapar palabras confusas El hombre la atraviesa por bosques de símbolos que le contemplan con miradas familiares

IV Correspondencias (Las flores del mal)

Los poemas describen imágenes, de apariencia banal pero pinceladas por las emociones y pensamientos, un profundo sentido de observación que se lamenta, critica y reflexiona. Baudelaire es un flaneur que vaga por las calles de París recuperando los rezagos de una ciudad que se moderniza. A punta de picos y palas se derrumban casas para abrir avenidas y nuevas vías más amplias como el boulevard que uniría el Louvre con Les Tulleries. La ciudad medieval se va quedando atrás para dar lugar a una moderna ciudad dominada por la burguesía y con ello cambian las costumbres y la forma de vivir. $\mathrm{Su}$ libro "Las flores del mal" es la representación gráfica de lo bueno y lo malo que hay en la ciudad y en el interior de los seres humanos. Baudelaire, en este libro -como en su vida- se comporta como la encarnación de un filósofo cínico de la Grecia clásica en el siglo XIX, denunciando con sus actos y sus palabras, ambas escandalosas, las incongruencias de la modernidad.

Sin embargo, en agosto de ese mismo año el sexto juzgado correccional entabla una demanda contra el poemario por atentar contra la moral pública y religiosa -el mismo juzgado que demandó a la novela "Madame Bovary"-. Flaubert utilizó una serie de ardides, entre ellos las influencias a los jueces. Con Baudelaire no fue igual, pues, por un lado titubeó hasta el final en conseguir influencias -a pesar de que era muy conocido en el ambiente artístico y periodístico-, y por el otro, los jueces ya no querían que sucediera lo de "Madame Bovary". El veredicto del juzgado descartó la acusación de ultraje a la moral religiosa, pero ordenó que sean retirados seis poemas de un total de cien. El juicio es tomado como una humillación por Baudelaire, pero los elogios posteriores de la crítica literaria y sus amigos en diversos medios escritos le hicieron ganar confianza en sí mismo. En ese periodo publica "Los paraísos artificiales", "Salón de 1859", un trabajo sobre Teophile Gautier y el de los caricaturistas franceses y extranjeros. Baudelaire consideraba más libres a los caricaturistas que a los pintores, quienes tenían que lidiar con el peso de sus antecesores. En ese tiempo publicó las traducciones de Poe: "Aventuras de Gordon Pym" y "Eureka".

En 1861, para la segunda edición de "Las flores del mal", Baudelaire añadió nuevos poemas más audaces, como le comentó en una carta a su editor Poulet- Malassis, "Nouvelles fleurs du mal". Rompen todo, como una explosión de gas en una cristalería". 
Con la esperanza de ganar más dinero y paliar sus angustias económicas ya que seguía pidiendo ayuda a su madre -y vérselas con el notario Ancelle-, vendiendo baratijas o libros autografiados a los mercachifles del Sena o pidiendo prestado a amigos o artistas -como Manet-.

Baudelaire conocía el éxito de otros escritores franceses en Bélgica o de las noticias sobre el éxito de Dickens en los Estados Unidos. Baudelaire viajó a Bélgica en abril de 1864 decidido a hacer dinero dando conferencias, pero la aventura no funcionó, más aun, fue un fracaso. Cuando sus amigos pensaron que volvería a París, Baudelaire se fue quedando dominado por una abulia que sus amigos llamaban provinciana. En los dos años que se quedó en Bélgica solo publicó mas traducciones de Poe y recopilaba poemas en prosa con la idea de darle unidad orgánica a una nueva obra; y, también, había completado decenas de cuadernos sobre Bélgica, sus personas y sus costumbres, a pesar de sentir cierta repulsión por su idiosincrasia que consideraba una caricatura de Francia, donde se acentuaban los defectos como el amor sin galantería, la impertinencia sin ingenio o el tomar cerveza en lugar de vino. Los cuadernos estaban apilados en treinta y tres estuches con la intención de compilarlos en un libro. Acaso su opinión sobre el país pueda resumirse en algunos de sus títulos tentativos: "Pobre Bélgica", "La grotesca Bélgica"Mientras pasaba los días en Bélgica, Baudelaire también recopilaba poemas en prosa publicados indistintamente en diversas revistas, su intención era completar cien de ellos. Lo que constituyó en el cuerpo de "Le Spleen de Paris", para lo cual negoció de manera caótica con su editor habitual en Francia, Poulet-Malassis, y un editor en Bruselas. "Le Spleen de Paris" se publicó póstumamente en 1868 , contiene piezas notables producto de su aguda observación.

Son notables "Los perros buenos", consagrada sobre todo al perro pobre, sin casa, al vagabundo, al saltimbanqui, al perro que como el actor, el pobre y el bohemio, tiene el instinto maravillosamente aguijoneado por la necesidad, madre tan buena y verdadera patrona de la inteligencia! También lo es "Madeimoiselle Bistouri", el relato de una cocotte parisina, quien una noche aborda al narrador a quien confunde con un médico y lo invita a su casa luego de un pequeño dialogo y el sujeto accede más por curiosidad. Aquella casa era un tugurio y en una de sus paredes reposaban las litografías de tres eminentes médicos de la época. A pesar de la pobreza el sitio era bastante acogedor, la dama lo invita a sentirse como en su casa, es decir el hospital. Minutos más tarde, luego de unas copas de vino, la dama le muestra un grupo de pequeños paquetes cada uno con fotos de médicos, cirujanos, internos y externos, de diversos hospitales como La Pitié, fotos que atesora como trofeos de guerra, por ello la dama le pide al narrador que le lleve una foto la próxima vez que la visite. Cuando le pregunta por qué la fijación con los médicos, ella con un tono de tristeza responde que no lo sabe ...o no lo recuerda. Que rarezas no se encuentran en una gran ciudad cuando se sabe caminar y mirar. La vida está llena de monstruos inocentes.

Pareciera que con este relato Baudelaire insinúa que la crème de la crème de la medicina mundial del siglo XIX, el hospital La Pitié-Salpêtrière disfruta también de la bohemia parisina.

\section{ANY WHERE OUT OF \\ THE WORLD \\ En Cualquier Parte \\ Fuera del Mundo}

Esta vida es un hospital donde cada enfermo está poseído por el deseo de cambiar de cama. Este querría sufrir frente a la estufa, y aquel cree que sanaría al lado de la ventana. Me parece que yo siempre estaría bien allí donde no estoy, y este tema de la mudanza es uno de los que discuto incesantemente con mi alma.

De "El Spleen de París". 
Para mediados del siglo XIX, el spleen era un término utilizado por la medicina inglesa -del que eran sinónimos la hipocondría, los vapores y la histeriapara denotar a la melancolía. Pero spleen, nombre dado también al bazo, es un nombre asociado a la teoría hipocrática y galénica de los humores como la fuente de la bilis negra. De acuerdo a esta teoría, el exceso de bilis negra daba lugar a la melancolía, esa sensación de hastío y síntomas mentales que eran producto de los vapores producidos en el hipocondrio y que ascendían al cerebro como el "humo de la chimenea". La melancolía producía -de acuerdo a Robert Burton y otros autorestemor, tristeza, aburrimiento, pesadez, delusiones y quimeras (alucinaciones) que por un lado abatía las mentes y la voluntad, y por el otro, a decir de Aristóteles, era una condición para el desarrollo de la creatividad artística. El spleen, era también esa condición de tristeza crónica que era como cargar todas las culpas y la desazón del mundo.

Baudelaire, el poeta huraño, aquel que se vestía de negro con el pelo pintado de verde. Vagabundo de la noche y de los hoteles baratos había agudizado su sentido de observación y perspicacia para descubrir las grietas más profundas de la condición humana. Ausente de la bohemia parisina, Baudelaire recibe en 1865, tanto de Mallarmé como Verlaine, ambos poetas simbolistas, elogiosos comentarios a su obra. La estadía en Bélgica no fue buena; así, cierto día de 1866, Baudelaire sufre un sincope estando en la iglesia Saint Loupe en la localidad de Namur, queda con hemiplejia, ya para eso en sus cartas Baudelaire refería sentirse cansado y con dificultad para tejer ideas. Debido al síncope es trasladado a Bruselas. Por su condición, su madre viaja para llevarlo de vuelta a París y es internado en la clínica del doctor Duval, cerca de la Place de l'Etoile.

Su agonía duró dieciocho meses, con una hemiplejía derecha y una afasia que solo le permitían decir "Cré nom!", una abreviación de "Sacré nom de Dieu!, y el poeta quedó confinado a la tiranía de dos palabras que trataba de cambiar de significado al expresarlas con diferentes entonaciones. A decir de su neurólogo, Charles Lasegue, con tal grado de afasia le era imposible discernir si sus emociones e inteligencia estaban conservadas.

A su muerte, que ocurrió acompañado de su madre, lo lloraron sus amigos cercanos y la ciudad literaria de París. Charles Asselinau, su eterno amigo, pronunció la elegía funeraria y a decir de algunos testigos lo hizo sollozando. Fue enterrado, por disposición de su madre, donde nunca quiso estar, en una tumba al costado de su padrastro Aupick, y en su lápida no se mencionó su condición de poeta. Muchos años atrás, en Constantinopla, a medio camino por su viaje al Oriente, dos jóvenes, Flaubert y Maxime du Camp, estaban en una cena con el embajador de Francia y su esposa, es decir Aupick, quien por buscar tema de conversación preguntó a los jóvenes sobre nuevos escritores franceses, y le respondieron que sí y que "hay un tal Baudelaire que ha demostrado un gran talento", le mencionaron. El embajador frunció el ceño, imaginando que le jugaban una broma, y la esposa discretamente bajó la mirada.

Baudelaire con su estilo de dandy decadente, vivió los vestigios de un romanticismo que estaba de salida. Sin saberlo estaba inaugurando un nuevo estilo, el de la modernidad, él, quien detestaba el progreso pues no era capaz con todo su poder de amenguar la bêtise de la gente. A decir de Walter Benjamin, Baudelaire fue el poeta de los inicios del capitalismo. Lo vivió intensamente, confrontando las convenciones no solo con sus actos sino con una poesía agresiva en los detalles y las ideas. Amante del dibujo y la pintura, sus poemas están cargados de color y de contraste, como el azur, ese azul del cielo que lo acogía de día y de noche en su flânnerie por la ciudad de París. Un majestuoso albatros de la poesía y un ser humano común con todos sus altibajos en una urbe que ingresaba a la modernidad.

A peine les ont-ils déposés sur les planches, Que ces rois de l'azur, maladroits et honteux, 
Laissent piteusement leurs grandes ailes blanches

Comme des avirons traîner à côté d'eux. ${ }^{1}$

L`Albatros, Les fleurs du mal

Se habla mucho del consumo de sustancias, pero a pesar de que demuestra haber consumido varias no era adicto sino mas bien era un gran procastinador y sufría de melancolía, eso sí consumidor de vino. En "Los paraísos artificiales" menciona del vino que era "semejante al hombre, no sabe jamás hasta qué punto se le puede estimar o despreciar, amar o aborrecer". Del hachís decía que "no consuela como el vino pues desarrolla desmedidamente la personalidad humana y no lo recomienda cuando el ánimo se siente inclinado al spleen". Comparte la idea de que "los grandes poetas, los filósofos, los profetas son seres que mediante el puro y libre ejercicio de la voluntad llegan a un estado en el que son al mismo tiempo, la causa y el efecto, el sujeto y el objeto, el hipnotizador y el sonámbulo". Deja para los médicos un estudio más profundo de los estimulantes, entre los cuales menciona a la "coca o erythroxylon, esa singular planta cuyas hojas masticadas aumentan la energía y suprimiendo el apetito".

Baudelaire confrontó a todos, incluidos los lectores, para muestra el poema que abre "Las flores del mal".

AL LECTOR ${ }^{2}$

El pecado, el error, la idiotez, la avaricia, nuestro espiritu ocupan y el cuerpo nos desgastan, y a los remordimientos amables engordamos, igual que a sus parásitos los pordioseros nutren.

1 Apenas los colocan sobre la cubierta/Esos reyes del cielo azul, torpes y avergonzados/ lastimosamente dejan sus grandes alas blancas/ Como remos que se arrastran a sus costados. (traducción del autor del artículo)

2 La traducción ha sido adaptada de la edición de Las flores del mal publicada por Ediciones Cátedra con algunas modificaciones del autor del presente artículo
Nuestro pecar es terco, la contrición cobarde; Cómodamente hacemos pagar la confesión, $y$ volvemos alegremente al camino cenagoso, pensando que un vil llanto lave todas las faltas.

Sobre la almohada del mal está Satán

Trismegisto

Que largamente mece nuestro espiritu hechizado,

$Y$ el preciado metal de nuestra voluntad

Este sabio alquimista por completo evapora.

¡El Diablo los hilos que nos mueven sujeta! Encontramos encanto en cosas repugnantes; hacia el Infierno damos un paso cada día, sin horror, a través de las tinieblas que hieden.

Igual que un libertino pobre que besa y muerde el seno martirizado de una vieja ramera, Robamos, al pasar, un placer clandestino Que exprimimos con fuerza cual vieja naranja.

Preso y hormigueante, como un millón de helmintos, un pueblo de Demonios nos bulle en el cerebro, $Y$, cuando respiramos, la Muerte a los pulmones

Baja, río invisible, con apagadas quejas.

Si el estupro, el veneno, el puñal, el incendio, no bordaron aún con sus placenteros diseños El banal cañamazo de nuestra suerte misera, Es porque nuestra alma, ;ay! no es lo bastante osada.

Pero, entre los chacales, las panteras, los linces, los simios, los escorpiones, los gavilanes, las serpientes, los monstruos aulladores, gritadores, rampantes En el infame zoológico de nuestras corrupciones,

¡Hay uno más feo, más malvado, más inmundo! Aunque no gesticule ni lance grandes gritos, Gustosamente haría de la tierra un despojo 
$Y$ en un bostezo al mundo engulliría: ¿Es el hastío! -el ojo lleno de involuntario llanto, sueña cadalsos mientras fuma su pipa, Lector, tú ya conoces este monstruo exquisito, -Hipócrita lector -mi semejante, -jmi hermano!

\section{Nota del autor}

La oportunidad de revisar a un poeta audaz y de confrontación permite algunas digresiones, así, el autor del presente artículo inició su vida literaria escribiendo en un periódico mural en la secundaria de un colegio de curas. El título del mural era "Hipócrita lector", título sugerido por el profesor que nos animó en la idea. Siendo adolescentes no entendimos en su momento todo el significado de aquellas palabras, pero el periódico perduró hasta que terminamos el colegio, sin sufrir ninguna censura eclesiástica a pesar de algunos temas que escribimos, acaso porque nuestras calificaciones siempre fueron sobre el promedio o por un golpe de suerte.

\section{Fuentes bibliográficas}

1. Baudelaire, Charles

- $\quad$ Le Spleen de Paris. Paris: Éditions Gallimard; 2010.

- $\quad$ Les Fleurs du Mal. Paris: Éditions Gallimard; 2020.

- $\quad$ Las flores del mal. Madrid: Ediciones Cátedra; 2014.

- Los paraísos artificiales, El spleen de París. Buenos Aires: Editorial Losada; 1992.

2. Calasso, Roberto. La Folie Baudelaire. Barcelona: Editorial Anagrama; 2011.

3. Asselinau, Charles. Charles Baudelaire, su vida y su obra. Valencia: Editorial Pre-Textos; 2004.

4. Raitt AW. On Le Spleen de Paris. Nineteenth-Century French Studies, Vol. 18, No. 1/2 (Fall-Winter 1989-1990), pp. 150-164.

5. Zapata, Juan. Baudelaire: traductor-autocritas. Literatura: teoría, historia, crítica 19.2 (2017): 19-50.

6. Dieguez S. · Bogousslavsky J. Baudelaire's Aphasia: From poetry to cursing. En: Bogousslavsky J, Hennerici MG (eds): Neurological Disorders in Famous Artists - Part 2. Front Neurol Neurosci. Basel, Karger, 2007, vol 22, pp 121-14.

\section{Correspondencia:}

Aldo Vivar-Mendoza

aldo.vivar.m@upch.pe

Fecha de recepción: 21-08-2021.

Fecha de aceptación: 31-08-2021.

Conflicto de interés: ninguno, según el autor.

Financiamiento: por el autor. 